\title{
A Relationship Between Mortality and Eating Breakfast and Fiber
}

Dana E King, MD, MS and Jun Xiang, MS, MA

Background: Recent studies suggest that intermittent fasting or skipping breakfast may be good strategies for weight loss and better health. The objective of this study was to determine whether regular breakfast is associated with overall or cardiovascular mortality.

Methods: Cohort study with follow-up mortality data from the NHANES 1999-2002. National weighted sample. Outcomes were overall and cardiovascular mortality; secondary was fiber intake.

Results: Out of 5761 participants, there were 4778 (82.9\%) identified as breakfast eaters and 2027 deaths $(35.2 \%)$; $469(23.1 \%)$ deaths were due to cardiovascular diseases. The average daily intake of calories was 2015 , and fiber was $16.3 \mathrm{~g}$ /day. A total of $17.7 \%, 66.0 \%$, and $11.4 \%$ of participants had diabetes, hypertension, and cardiovascular diseases, respectively. Analysis showed breakfast eaters were older, had lower body mass index, and ate more calories and fiber daily than non-breakfast eaters. Cox proportional hazard regression analyses showed that compared to non-breakfast eaters, the breakfast eaters were less likely to experience mortality after multivariable adjustments (overall mortality: hazard ratio [HR], 0.69; 95\% confidence interval [CI], 0.57-0.84 and cardiovascular mortality: HR, $0.45 ; 95 \% \mathrm{CI}, 0.32-0.63)$. For the breakfast eaters, fiber intake $>25 \mathrm{~g} /$ day was associated with $21 \%$ (HR, 0.79; 95\% CI, 0.66-0.96) reduction in all-cause mortality after multivariable adjustments.

Conclusions: Regular daily intake of breakfast appears to be associated with lower overall and cardiovascular mortality, particularly when consuming fiber $>25$ g/day. Further studies examining specific breakfast foods and the timing of foods would be helpful. ( $\mathrm{J}$ Am Board Fam Med 2021;34:678-687.)

Keywords: Breakfast, Cardiovascular Diseases, Cohort Studies, Dietary Fiber, Feeding Behavior, Mortality, Nutrition Surveys, Regression Analysis

\section{Introduction}

Breakfast has been promoted as the healthiest meal of the day for many years in popular culture. ${ }^{1,2}$ Recent studies suggest that eating breakfast is associated with reduced cardiovascular morbidity and mortality. ${ }^{3,4}$ In recent work by Rong and colleagues that included 6550 participants followed for 17-23 years, after multivariable adjustment, participants who never consumed breakfast compared with

This article was externally peer reviewed.

Submitted 1 February 2021; revised 14 April 2021; accepted 16 April 2021.

From the Department of Family Medicine, West Virginia University School of Medicine, Morgantown, WV 26505 (DEK, JX).

Funding: None.

Conflict of interest: There are no conflicts of interest associated with this study or manuscript.

Corresponding author: Dana E. King, MD, MS, Department of Family Medicine, West Virginia University, PO Box 9152, One Medical Center Drive, Morgantown, West Virginia 26506, Phone: 304-581-1640, Fax: 304-5811646 (E-mail: kingdana@wvumedicine.org). those consuming breakfast every day had hazard ratios of 1.87 (95\% confidence interval [CI], 1.143.04) for cardiovascular mortality but not all-cause mortality. ${ }^{5}$ Two other recent cohort studies have found reduced all-cause and cardiovascular mortality in breakfast eaters. ${ }^{6,7}$ However, less is known regarding which foods consumed at breakfast would be most beneficial.

Dietary fiber has been associated with lower mortality in several studies., ${ }^{8,9}$ Many common breakfast foods such as oatmeal, cereal, and fruit are commonly consumed as breakfast foods and are high in fiber and may be contributing to the benefit of breakfast on mortality. Thus, dietary fiber should be considered and evaluated as an important mediator in the association between breakfast and mortality. However, specific data regarding fiber as a factor in the association of breakfast and mortality are lacking. Long-term cohorts that include fiber intake would help illuminate its role and clarify the relationship between breakfast and mortality. 
The objective of this study was to confirm the association between breakfast and mortality and determine whether fiber plays a key mediator role.

\section{Methods}

\section{Study Population}

The National Health and Nutrition Examination Survey (NHANES) is a series of nationally representative surveys conducted by the National Center for Health Statistics (NCHS). Using a complex and stratified multistage probability design, NHANES aims to evaluate the health and nutrition status of the non-institutionalized US population. Starting in 1999, the NHANES data, which includes participants' demographic characteristics, nutrition, health, and diet information, has been available from NHANES and released in 2 -year cycles. A home interview was followed by a physical examination in a mobile examination center (MEC) for all participants. The protocols for conducting the surveys were approved by the Center of Disease Control and Prevention Institutional Review Board, and all participants provided informed consent. Detailed study design and response rate can be found on the NHANES website. $^{10}$

\section{Study Participants}

The current study sample consists of 5761 participants, ages 40 years and up, with available nonzero sampling weights, and reliable and meet minimum criteria dietary recall status, from NHANES 19992000 and 2001-2002. To assess the survival status of the participants, we merged the baseline survey data with the 2015 Public-use Linked Mortality File (LMF), which provides mortality follow-up data from the date of survey participation through December 31, 2015. Information extracted from this LMF includes vital status, the number of person-months of follow-up from NHANES examination date, and the underlying leading cause of death, identified according to the $10^{\text {th }}$ revision of the International Statistical Classification of Diseases, Injuries, and Causes of Death (ICD-10) code. ${ }^{11} \mathrm{We}$ excluded the participants with missing vital status from the study.

\section{Mortality Outcomes}

The primary outcomes of the current study were all-cause mortality and CVD mortality. We defined all-cause mortality using the mortality status variable 'MORTSTAT,' coded as ' 0 ' if assumed alive and ' 1 ' if assumed deceased. All-cause mortality was identified based on nine following cause-specific death categories from the standardized list of 113 cause of death derived from ICD-10: heart diseases, cancer (malignant neoplasms), chronic lower respiratory disease, cerebrovascular diseases, diabetes, pneumonia and influenza, Alzheimer's disease, kidney disease, and unintentional injuries. We defined CVD mortality if the underlying leading cause of death was either heart disease or cerebrovascular disease. Follow-up time was determined as personmonths from the date of the NHANES MEC examination to the date of death or the end of the mortality period (December 15, 2015).

\section{Breakfast Eating Status}

The 1999-2000 and 2001-2002 NHANES used 1day 24-hour recall to collect dietary intake data. The participants were asked to recall types and amounts of foods and beverages consumed during the previous 24-hour period. We determined breakfast eating status according to the name of eating occasion (breakfast, lunch, dinner/supper, etc.) for individual foods identified by the participants. If a participant selected 'breakfast' or 'el desayuno' (Spanish for breakfast) as an eating occasion on the 24-hour diet recall, we defined the participant as a breakfast eater.

\section{Fiber and Covariates}

Demographic covariates including age, sex, race, body mass index (BMI), and education were extracted from the data. We combined four race categories: Non-Hispanic white, Non-Hispanic black, Hispanic, and Other Race. Education was divided into two levels of ' $\leq 11$ years' and ' $>11$ years' (completed high school or beyond). Daily total calorie intake from 24-hour dietary recall was considered as a dietary covariate. Calories and dietary fiber intake were extracted from the Total Nutrient Intakes file consisting of total nutrient intakes from foods and beverages and plain water consumed during the previous 24-hour time period. ${ }^{12}$

We grouped the daily fiber intake into 'High' ( $>25 \mathrm{~g})$ and 'Low' ( $\leq 25 \mathrm{~g})$, according to the American Heart Association recommendations for daily intake of dietary fiber of at least $25 \mathrm{~g} /$ day for adults. ${ }^{13,14}$ 
We also selected 3 chronic diseases, hypertension, diabetes, and cardiovascular diseases (CVD), as possible covariates, due to their relationship to diet and mortality. Hypertension and diabetes were defined when a participant had at least one of the following: told by a doctor, having an individual medical measurement equal or greater than the recommended threshold, and taking medication for the indicated disease. The medical measurement threshold for hypertension is average $130 \mathrm{mmHg}$ for systolic blood pressure and $85 \mathrm{mmHg}$ for diastolic blood pressure. ${ }^{15} \mathrm{We}$ chose hemoglobin A1c $\geq 6.5 \%$ as the cutoff for diabetes. ${ }^{16} \mathrm{~A}$ participant was categorized as having cardiovascular disease when he/she had at least one of three chronic conditions: congestive heart failure, coronary heart disease, or heart attack.

\section{Statistical Analysis}

All statistical analyses for the current study were conducted using SAS (version 9.4, 2013, SAS Institute Inc., Cary, NC). We incorporated appropriate 4-year sampling weights to account for the complex survey design, including oversampling, survey nonresponses, and post-stratification. SAS survey procedures were utilized following NHANES survey methods and analytic guidelines.

We conducted Chi-square analysis to examine the relationship between breakfast eating status and the participants' demographic characteristics. The prevalence of hypertension, diabetes, and CVD were also compared between the breakfast eaters and nonbreakfast eaters. Regression analysis was conducted to determine the difference in daily calorie and fiber intake between the 2 groups. Cox proportional hazard ratios $^{17}$ (HRs) with 95\% confidence intervals (CIs) were estimated for death from all-cause and CVD associated with breakfast eating status. We calculate HRs for unadjusted and multivariableadjusted models. Age, sex, race, BMI, education, daily calorie intake, daily fiber intake, hypertension, diabetes, and CVD (not included for CVD mortality outcome) were covariates for multivariable-adjusted model. We also calculated unadjusted and multivariable-adjusted HRs for all-cause and CVD mortality associated with the amount of fiber intake for the breakfast eaters and the non-breakfast eaters separately. All tests were 2 -tailed, $P$ value $<.05$ was considered statistical significance.

\section{Results}

Out of the 5761 participants, there were 2853 (49.5\%) males and 4778 (82.9\%) identified as breakfast eaters. The mean age of the participants was 57 years. The average daily intake of calories was higher for breakfast eaters than for non-breakfast eaters (2041.1 vs. $1871.1 ; P=.0001$ ). For fiber, breakfast eaters ate more fiber daily than non-breakfast eaters (16.9 g vs. 12.8 g; $P<.0001)$. There were $17.7 \%$, $66.0 \%$, and $11.4 \%$ of participants who had diabetes, hypertension, or CVD, respectively. Chi-square analyses showed that the breakfast eaters also were more likely to be white and have higher education, diabetes, and hypertension (Table 1).

During an average of 147.6 months of followup, there were 2027 (35.2\%) all-cause deaths and 469 (8.1\%) CVD deaths. Table 2 displays the results of the Cox proportional hazard regression analyses for the association between breakfast eating status and all-cause mortality and CVD mortality. The results of the unadjusted model showed no significant association between breakfast eating status and all-cause mortality and CVD mortality. However, after multivariable adjustment for factors including age, gender, race, BMI, education, total daily calorie and fiber intake (continuous), diabetes, hypertension, and CVD (excluded when estimating hazard ratio for CVD death), the association between breakfast and mortality had an HR of 0.69 (95\% CI, 0.57-0.84) for all-cause mortality and 0.45 (95\% CI, 0.32-0.63) for CVD mortality.

Regarding the role of fiber, we also present the unadjusted and multivariable-adjusted HRs for association between fiber intake $(\leq 25 \mathrm{~g} /$ day or $>25$ $\mathrm{g} /$ day) and mortality according to breakfast eating status in Tables 3 and 4. Focusing first on breakfast eaters in Table 3, fiber intake $>25 \mathrm{~g} /$ day was associated with a $27 \%$ reduction $(\mathrm{HR}, 0.73 ; 95 \% \mathrm{CI}$, $0.61-0.88)$ in unadjusted all-cause mortality and a $21 \%$ reduction ( $\mathrm{HR}, 0.79$; 95\% CI, 0.66-0.96) in all-cause mortality after multivariable adjustments.

Focusing only on non-breakfast eaters (Table 4), there was no significant association between the amount of fiber intake and mortality in the unadjusted or in the multivariable-adjusted analyses.

Examining the relationship in more detail, we evaluated the association with mortality according to 4 groups: breakfast and non-breakfast eaters and high ( $>25 \mathrm{~g} /$ day) and low fiber groups. The results are shown in Table 5 . The reference group 
Table 1. Demographic Characteristics of 1999-2002 NHANES Participants Aged 40 Years or Older By Breakfast Eating Status $(\mathrm{n}=5761)$

\begin{tabular}{|c|c|c|c|}
\hline & Breakfast Eater $(n=4778)$ & Non-breakfast Eater $(\mathrm{n}=983)$ & \\
\hline Characteristics & $\%(95 \% \mathrm{CI})$ & $\%(95 \% \mathrm{CI})$ & $P$ value \\
\hline \multicolumn{4}{|l|}{ Sex } \\
\hline Male & $46.6(45.2-48.0)$ & $48.8(44.5-53.0)$ & \multirow[t]{2}{*}{.34} \\
\hline Female & $53.4(52.0-54.8)$ & $51.2(47.0-55.5)$ & \\
\hline \multicolumn{4}{|l|}{ Race } \\
\hline Non-Hispanicwhite & $78.8(75.5-82.0)$ & $63.9(58.5-69.2)$ & \multirow[t]{4}{*}{$<.0001^{\|}$} \\
\hline Non-Hispanicblack & $8.3(6.1-10.5)$ & $17.9(13.1-22.7)$ & \\
\hline Hispanic & $9.5(6.2-12.8)$ & $13.2(6.7-19.7)$ & \\
\hline Other & $3.5(2.5-4.4)$ & $5.0(2.3-7.7)$ & \\
\hline \multicolumn{4}{|l|}{ Education } \\
\hline$\geq$ High school & $78.9(76.8-80.9)$ & $65.8(61.8-69.9)$ & \multirow[t]{2}{*}{$<.0001^{\|}$} \\
\hline$<$ High school & $21.1(19.1-23.2)$ & $34.2(30.1-38.2)$ & \\
\hline \multicolumn{4}{|l|}{ Diabetes } \\
\hline Yes & $13.4(12.0-14.9)$ & $10.1(7.8-12.4)$ & \multirow[t]{2}{*}{$.02^{\ddagger}$} \\
\hline No & $86.6(85.1-88.0)$ & $89.9(87.6-92.2)$ & \\
\hline \multicolumn{4}{|l|}{ Hypertension } \\
\hline Yes & $60.1(57.2-63.0)$ & $55.2(50.5-59.9)$ & \multirow[t]{2}{*}{$.01^{\ddagger}$} \\
\hline No & $39.9(37.0-42.8)$ & $44.8(40.1-49.5)$ & \\
\hline \multicolumn{4}{|l|}{ Cardiovascular disease } \\
\hline Yes & $9.9(8.5-11.4)$ & $11.0(8.2-13.8)$ & \multirow[t]{2}{*}{.46} \\
\hline \multirow[t]{2}{*}{ No } & $90.1(88.6-91.5)$ & $89.0(86.2-91.8)$ & \\
\hline & Mean $(95 \% \mathrm{CI})$ & Mean $(95 \% \mathrm{CI})$ & $P$ value $^{\dagger}$ \\
\hline Age & $57.5(56.9-58.1)$ & $53.0(51.9-54.0)$ & $<.0001^{\|}$ \\
\hline Body mass index & $28.4(28.0-28.8)$ & $29.1(28.4-29.9)$ & $.04^{\ddagger}$ \\
\hline Fiber intake & $16.9(16.1-17.7)$ & $12.8(12.0-13.6)$ & $<.0001^{\Perp}$ \\
\hline Calorie intake & $2041.1(2005.8-2076.4)$ & $1871.1(1798.5-1943.8)$ & $.0001^{\|}$ \\
\hline
\end{tabular}

CI, confidence interval; NHANES, National Health and Nutrition Examination Survey.

${ }^{*} P$ value was estimated from Chi-square analysis.

${ }^{\dagger} P$ value was estimated from regression analysis.

${ }^{\ddagger} P<0.05$.

${ }^{\S} P<0.01$.

${ }^{\text {" }} P<0.001$.

breakfast-low fiber was selected to evaluate the high fiber groups compared to it. As seen in Table 5, the breakfast eater-high fiber group has significantly lower all-cause mortality, $21 \%$ lower than the breakfast-low fiber group (HR, 0.79; 95\% CI, 0.660.95). Further, the non-breakfast eater-high fiber group does not have lower all-cause or CVD mortality than the breakfast-low fiber group. The nonbreakfast-low fiber group has higher mortality than the reference group.

\section{Discussion}

The findings of the current study support a significant association between eating breakfast and lower all-cause and CVD mortality after adjustment and a significant role in fiber intake. The association was not evident in uncontrolled analyses, likely due to the older average age of individuals who eat breakfast. Once the likely confounding factors of age and other sociodemographic risk factors were included in the model, the association between breakfast and mortality was evident. The addition of fiber as a factor revealed the importance of fiber at breakfast. While there was no association between fiber and mortality in non-breakfast eaters, breakfast eaters with high fiber intake had a $21 \%$ reduction in allcause mortality after adjustment when compared to breakfast eating low fiber counterparts

The direction of the association is consistent with previous studies documenting the value of eating breakfast or the ill health associated with 
Table 2. Unadjusted and Adjusted Hazard Ratio for All-Cause Mortality and Cardiovascular Mortality ( $\mathrm{n}=5761$ )

\begin{tabular}{|c|c|c|c|c|}
\hline \multirow[b]{2}{*}{ Models } & \multicolumn{2}{|c|}{ Total Mortality $(\mathrm{n}=2027)$} & \multicolumn{2}{|c|}{ Cardiovascular Mortality $(\mathrm{n}=469)$} \\
\hline & Hazard Ratio (95\% CI) & $P$ value ${ }^{*}$ & Hazard Ratio (95\% CI) & $P$ value* \\
\hline \multicolumn{5}{|l|}{ Unadjusted } \\
\hline Breakfast Eater & $1.02(0.9-1.2)$ & .81 & $0.77(0.57-1.05)$ & .09 \\
\hline Non-eater & - & & - & \\
\hline \multicolumn{5}{|l|}{ Multivariate adjusted } \\
\hline \multicolumn{5}{|l|}{ Breakfast } \\
\hline Eater & $0.69(0.57-0.84)$ & $.0005^{\S}$ & $0.45(0.32-0.63)$ & $<.0001^{\S}$ \\
\hline Non-eater & - & & - & \\
\hline Age & $1.09(1.08-1.09)$ & $<.0001^{\S}$ & $1.10(1.09-1.11)$ & $<.0001^{\S}$ \\
\hline \multicolumn{5}{|l|}{ Sex } \\
\hline Male & - & & - & \\
\hline Female & $0.68(0.59-0.78)$ & $<.0001^{\S}$ & $0.52(0.41-0.67)$ & $<.0001^{\S}$ \\
\hline \multicolumn{5}{|l|}{ Race } \\
\hline Non-Hispanic white & - & & - & \\
\hline Non-Hispanic black & $1.11(0.88-1.39)$ & .36 & $1.28(0.83-1.97)$ & .26 \\
\hline Hispanic & $0.85(0.67-1.08)$ & .18 & $0.92(0.56-1.51)$ & .72 \\
\hline Other & $0.73(0.40-1.33)$ & .30 & $0.28(0.07-1.11)$ & .07 \\
\hline Body mass index & $0.99(0.98-1.01)$ & .45 & $0.99(0.97-1.03)$ & .78 \\
\hline \multicolumn{5}{|l|}{ Education } \\
\hline$\geq$ High school & - & & - & \\
\hline$<$ High school & $1.27(1.11-1.44)$ & $.0008^{\S}$ & $1.08(0.76-1.54)$ & .64 \\
\hline \multicolumn{5}{|l|}{ Diabetes } \\
\hline Yes & $1.44(1.22-1.69)$ & $<.0001^{\S}$ & $1.94(1.39-2.69)$ & $.0003^{\S}$ \\
\hline No & - & & - & \\
\hline \multicolumn{5}{|l|}{ Hypertension } \\
\hline Yes & $1.28(1.12-1.45)$ & $.0005^{\S}$ & $2.11(1.27-3.50)$ & $.005^{\ddagger}$ \\
\hline No & - & & - & \\
\hline \multicolumn{5}{|l|}{ Cardiovascular disease } \\
\hline Yes & $1.63(1.35-1.96)$ & $<.0001^{\S}$ & & \\
\hline No & - & & & \\
\hline Daily calorie intake & $1.0(1.0-1.0)$ & .50 & $1.0(1.0-1.0)$ & .92 \\
\hline Daily fiber intake & $0.98(0.97-0.99)$ & $.01^{\dagger}$ & $0.99(0.98-1.01)$ & .78 \\
\hline
\end{tabular}

CI, confidence interval.

${ }^{*} P$ value estimated per Cox proportional hazards models.

${ }^{\dagger} P<0.05$.

${ }^{\ddagger} P<0.01$.

${ }^{\S} P<0.001$.

skipping breakfast. Ma and colleagues ${ }^{18}$ conducted a systematic review and meta-analysis of breakfast in relation to the risk of overweight/obesity and found the likelihood of developing either was greater in individuals skipping breakfast (odds ratio [OR], 1.31; 95\% CI, 1.17-1.47). In another metaanalysis, $\mathrm{Bi}$ and colleagues ${ }^{4}$ examined the risk of developing type 2 diabetes and found that the pooled adjusted relative risk (RR) was $21 \%$ higher for skipping breakfast (RR, 1.21; 95\% CI, 1.121.31). Ofori-Asenso and colleagues systematically reviewed the association of breakfast and cardiometabolic risk factors, ${ }^{19}$ and found that people who regularly skipped breakfast also were $21 \%$ more likely (HR, 1.21; 95\% CI, 1.08-1.35; $I^{2}=17.3 \%$, $P=.304)$ to experience incident cardiovascular disease or die from it than people who regularly consumed breakfast. These systematic reviews include dozens of studies and are supportive of the value of breakfast.

Breakfast appears to be beneficial, but what people eat for breakfast likely matters a great deal. Our 
findings demonstrated that breakfast's mortality benefit was linked to fiber intake, with a significant reduction in mortality evident in the high fiberbreakfast group that was not seen in non-breakfast eaters or non-breakfast-high fiber groups.

In consideration of possible mechanisms for the observed association, in the current study, breakfast eaters had higher levels of diabetes and ate more calories, both of which confounds the conventional wisdom of beneficial lifestyles and subsequent health. One possibility to explain the findings includes increased fiber intake among breakfast eaters, which was present in our study. $\mathrm{Ma}$ and colleagues ${ }^{18}$ showed an association between dietary fiber and inflammation in the Women's Health Initiative Observational Study, including lower IL-6 and TNF-alpha values. King and colleagues ${ }^{20}$ found lower C-reactive protein levels in clinical trial participants randomized to a high fiber diet. Several other studies have found

Table 3. Unadjusted and Adjusted Hazard Ratio for All-Cause Mortality and Cardiovascular Mortality Among Breakfast Eaters $(n=4778)$

\begin{tabular}{|c|c|c|c|c|}
\hline \multirow[b]{2}{*}{ Models } & \multicolumn{2}{|c|}{ Total Mortality $(\mathrm{n}=1719)$} & \multicolumn{2}{|c|}{ Cardiovascular Mortality $(\mathrm{n}=383)$} \\
\hline & Hazard Ratio (95\% CI) & $P$ value* & Hazard Ratio (95\% CI) & $P$ value* \\
\hline \multicolumn{5}{|l|}{ Unadjusted } \\
\hline \multicolumn{5}{|l|}{ Fiber intake, $g$} \\
\hline$>25$ & $0.73(0.61-0.88)$ & $.002^{\ddagger}$ & $0.74(0.49-1.13)$ & .16 \\
\hline$\leq 25$ & - & & - & \\
\hline \multicolumn{5}{|l|}{ Multivariable-adjusted } \\
\hline \multicolumn{5}{|l|}{ Fiber intake, $g$} \\
\hline$>25$ & $0.79(0.66-0.96)$ & $.02^{\dagger}$ & $0.84(0.51-1.37)$ & .46 \\
\hline$\leq 25$ & - & & - & \\
\hline Age & $1.09(1.08-1.10)$ & $<.0001^{\S}$ & $1.11(1.09-1.13)$ & $<.0001^{\S}$ \\
\hline \multicolumn{5}{|l|}{ Sex } \\
\hline Male & - & & - & \\
\hline Female & $0.68(0.58-0.80)$ & $<.0001^{\S}$ & $0.53(0.38-0.76)$ & $.001^{\ddagger}$ \\
\hline \multicolumn{5}{|l|}{ Race } \\
\hline Non-Hispanic white & - & & - & \\
\hline Non-Hispanic black & $1.07(0.86-1.34)$ & .53 & $1.18(0.76-1.84)$ & .44 \\
\hline Hispanic & $0.91(0.71-1.16)$ & .43 & $0.91(0.50-1.64)$ & .74 \\
\hline Other & $0.77(0.42-1.43)$ & .40 & $0.21(0.05-0.97)$ & $.04^{\dagger}$ \\
\hline Body mass index & $0.99(0.98-1.01)$ & .73 & $1.01(0.98-1.05)$ & .55 \\
\hline \multicolumn{5}{|l|}{ Education } \\
\hline$\geq$ High school & - & & - & \\
\hline$<$ High school & $1.24(1.08-1.43)$ & $.004^{\ddagger}$ & $1.07(0.74-1.55)$ & .70 \\
\hline \multicolumn{5}{|l|}{ Diabetes } \\
\hline Yes & $1.52(1.29-1.78)$ & $<.0001^{\S}$ & $1.73(1.19-2.51)$ & $.005^{\ddagger}$ \\
\hline No & - & & - & \\
\hline \multicolumn{5}{|l|}{ Hypertension } \\
\hline Yes & $1.25(1.09-1.44)$ & $.003^{\ddagger}$ & $2.54(1.46-4.42)$ & $.002^{\ddagger}$ \\
\hline No & - & & - & \\
\hline \multicolumn{5}{|l|}{ Cardiovascular disease } \\
\hline Yes & $1.61(1.35-1.92)$ & $<.0001^{\S}$ & & \\
\hline No & - & & & \\
\hline Daily calorie intake & $1.0(1.0-1.0)$ & .50 & $1.0(1.0-1.0)$ & .92 \\
\hline
\end{tabular}

CI, confidence interval.

${ }^{*} P$ value estimated per Cox proportional hazards models.

${ }^{\dagger} P<0.05$.

${ }^{\ddagger} P<0.01$.

${ }^{\circledR} P<0.001$. 
an association of fiber intake with inflammatory biomarkers. ${ }^{21-23}$

Another possibility is that food timing (eating breakfast) has an impact on chronic inflammation. In a study by Zhu and colleagues, ${ }^{23}$ skipping breakfast was associated with higher levels of inflammatory biomarkers $(P<.001)$. Eating breakfast may activate certain pathways that inhibit inflammation.

An additional possibility is that eating breakfast is associated with other healthy lifestyle habits or attributes. Such factors as unaccounted aspects of the diet, physical activity, alcohol intake, or other healthy habits may be indirectly associated with breakfast and may have an impact on cardiovascular and overall health that may have affected the findings of the current study. ${ }^{24-26}$

The limitations of the study include that the diet intake was self-report and that individuals' changing food intake or breakfast frequency over the course of multiple years could not be taken into account.

Table 4. Unadjusted and Adjusted Hazard Ratio for All Cause of Mortality and Cardiovascular Mortality Among Non-Breakfast Eaters $(\mathrm{n}=983)$

\begin{tabular}{|c|c|c|c|c|}
\hline \multirow[b]{2}{*}{ Models } & \multicolumn{2}{|c|}{ Total Mortality $(\mathrm{n}=308)$} & \multicolumn{2}{|c|}{ Cardiovascular Mortality $(\mathrm{n}=86)$} \\
\hline & Hazard Ratio (95\% CI) & $P$ value* & Hazard Ratio (95\% CI) & $P$ value* \\
\hline \multicolumn{5}{|l|}{ Unadjusted } \\
\hline \multicolumn{5}{|l|}{ Fiber intake, $g$} \\
\hline$>25$ & $0.75(0.43-1.29)$ & .28 & $0.70(0.26-1.86)$ & .46 \\
\hline$\leq 25$ & - & & - & \\
\hline \multicolumn{5}{|l|}{ Multivariable-adjusted } \\
\hline \multicolumn{5}{|l|}{ Fiber intake, $g$} \\
\hline$>25$ & $0.62(0.33-1.16)$ & .13 & $0.51(0.18-1.43)$ & .19 \\
\hline$\leq 25$ & - & & - & \\
\hline Age & $1.07(1.05-1.09)$ & $<.0001^{\S}$ & $1.07(1.04-1.10)$ & $<.0001^{\$}$ \\
\hline \multicolumn{5}{|l|}{ Sex } \\
\hline Male & - & & - & \\
\hline Female & $0.66(0.47-0.94)$ & $.02^{\dagger}$ & $0.52(0.26-1.04)$ & .06 \\
\hline \multicolumn{5}{|l|}{ Race } \\
\hline Non-Hispanic white & - & & - & \\
\hline Non-Hispanic black & $1.27(0.79-2.04)$ & .25 & $1.62(0.78-3.39)$ & .19 \\
\hline Hispanic & $0.71(0.44-1.16)$ & .19 & $0.91(0.30-2.74)$ & .86 \\
\hline Other & $0.71(0.26-1.97)$ & .52 & $0.37(0.02-5.44)$ & .45 \\
\hline Body mass index & $0.98(0.96-1.01)$ & .15 & $0.94(0.89-1.01)$ & .08 \\
\hline \multicolumn{5}{|l|}{ Education } \\
\hline$\geq$ High school & - & & - & \\
\hline$<$ High school & $1.38(0.98-1.96)$ & $.02^{\dagger}$ & $1.11(0.55-2.24)$ & .76 \\
\hline \multicolumn{5}{|l|}{ Diabetes } \\
\hline Yes & $1.04(0.76-1.44)$ & .80 & $3.53(1.96-6.36)$ & $.0001^{\S}$ \\
\hline No & - & & - & \\
\hline \multicolumn{5}{|l|}{ Hypertension } \\
\hline Yes & $1.39(0.98-1.97)$ & .07 & $1.35(055-3.32)$ & .50 \\
\hline No & - & & - & \\
\hline \multicolumn{5}{|l|}{ Cardiovascular disease } \\
\hline Yes & $1.81(1.17-2.80)$ & $.01^{\dagger}$ & & \\
\hline No & - & & & \\
\hline Daily calorie intake & $1.00(1.00-1.00)$ & 0.76 & $1.00(1.00-1.00)$ & .88 \\
\hline
\end{tabular}

CI, confidence interval.

${ }^{*} P$ value estimated per Cox proportional hazards models.

${ }^{\dagger} P<0.05$.

${ }^{\ddagger} P<0.01$.

${ }^{{ }} P<0.001$. 
Further, the study was retrospective and not a prospective trial. The strengths of the study include utilizing a large representative national cohort, and the ability to control for likely confounding factors.

In conclusion, this study supports the association between eating breakfast and lower all-cause and cardiovascular mortality after possible confounding factors were taken into account. The study adds new information that high fiber intake in combination with breakfast may play a key role in overall health and longevity. Further research is needed for practicing physicians to be comfortable with recommending

Table 5. Unadjusted and Adjusted Hazard Ratio for All-Cause Mortality and Cardiovascular Mortality On Breakfast Eating Status and Fiber Intake ( $n=5761)$

\begin{tabular}{|c|c|c|c|c|}
\hline \multirow[b]{2}{*}{ Models } & \multicolumn{2}{|c|}{ Total Mortality $(n=2027)$} & \multicolumn{2}{|c|}{ Cardiovascular Mortality $(n=469)$} \\
\hline & Hazard Ratio (95\% CI) & $P$ value* & Hazard Ratio (95\% CI) & $P$ value* \\
\hline \multicolumn{5}{|l|}{ Unadjusted } \\
\hline \multicolumn{5}{|l|}{ Breakfast \& fiber } \\
\hline Breakfast eater-high fiber & $0.73(0.61-0.88)$ & $.002^{\ddagger}$ & $0.74(0.49-1.13)$ & .15 \\
\hline Breakfast eater-low fiber & - & & - & \\
\hline Non-breakfast eater-high fiber & $0.71(0.40-1.28)$ & .24 & $0.89(0.33-2.44)$ & .82 \\
\hline Non-breakfast eater-low fiber & $0.96(0.80-1.14)$ & .61 & $1.28(0.93-1.74)$ & .12 \\
\hline \multicolumn{5}{|l|}{ Multivariable-adjusted } \\
\hline \multicolumn{5}{|l|}{ Breakfast \& fiber } \\
\hline Breakfast eater-high fiber & $0.79(0.66-0.95)$ & $.02^{\dagger}$ & $0.82(0.50-1.35)$ & .42 \\
\hline Breakfast eater-low fiber & - & & - & \\
\hline Non-breakfast eater-high fiber & $0.84(0.45-1.57)$ & .57 & $1.28(0.45-3.61)$ & .63 \\
\hline Non-breakfast eater-low fiber & $1.53(1.27-1.86)$ & $<.0001^{\S}$ & $2.38(1.66-3.40)$ & $<.0001^{\S}$ \\
\hline Age & $1.08(1.07-1.09)$ & $<.0001^{\S}$ & $1.10(1.09-1.12)$ & $<.0001^{\S}$ \\
\hline \multicolumn{5}{|l|}{ Sex } \\
\hline Male & - & & - & \\
\hline Female & $0.68(0.59-0.78)$ & $<.0001^{\S}$ & $0.53(0.41-0.68)$ & $<.0001^{\S}$ \\
\hline \multicolumn{5}{|l|}{ Race } \\
\hline Non-Hispanic white & - & & - & \\
\hline Non-Hispanic black & $1.13(0.90-1.42)$ & .29 & $1.29(0.84-1.99)$ & .24 \\
\hline Hispanic & $0.85(0.66-1.08)$ & .17 & $0.92(0.56-1.51)$ & .73 \\
\hline Other & $0.74(0.40-1.37)$ & .33 & $0.28(0.07-1.16)$ & .08 \\
\hline Body mass index & $0.99(0.98-1.01)$ & .42 & $0.99(0.97-1.03)$ & .75 \\
\hline \multicolumn{5}{|l|}{ Education } \\
\hline$\geq$ High school & - & & - & \\
\hline$<$ High school & $1.28(1.12-1.47)$ & $.0007^{\S}$ & $1.09(0.76-1.56)$ & .63 \\
\hline \multicolumn{5}{|l|}{ Diabetes } \\
\hline Yes & $1.43(1.22-1.68)$ & $<.0001^{\S}$ & $1.94(1.38-2.71)$ & $.0004^{\S}$ \\
\hline No & - & & - & \\
\hline \multicolumn{5}{|l|}{ Hypertension } \\
\hline Yes & $1.28(1.13-1.46)$ & $.0004^{\S}$ & $2.11(1.28-3.50)$ & $.005^{\ddagger}$ \\
\hline No & - & & - & \\
\hline \multicolumn{5}{|l|}{ Cardiovascular disease } \\
\hline Yes & $1.63(1.35-1.97)$ & $<.0001^{\S}$ & & \\
\hline No & - & & - & \\
\hline Daily calorie intake & $1.00(1.00-1.00)$ & .87 & $1.00(1.00-1.00)$ & .90 \\
\hline
\end{tabular}

CI, confidence interval.

${ }^{*} P$ value estimated per Cox proportional hazards models.

${ }^{\dagger} P<0.05$.

${ }^{\ddagger} P<0.01$.

${ }^{\circledR} P<0.001$. 
specific foods at breakfast, and with determining what timing and selection of foods are most advantageous.

We would like to thank Caitlin Montgomery for her assistance with the manuscript.

To see this article online, please go to: http://jabfm.org/content/ 34/4/678.full.

\section{References}

1. Betts JA, Chowdhury EA, Gonzalez JT, Richardson JD, Tsintzas K, Thompson D. Is breakfast the most important meal of the day? Proc Nutr Soc 2016; 75(4):464-474.

2. Clayton DJ, James LJ. The effect of breakfast on appetite regulation, energy balance and exercise performance. Proc Nutr Soc 2016;75(3):319-327.

3. Takagi H, Hari Y, Nakashima K, Kuno T, Ando T. ALICE (All-Literature Investigation of Cardiovascular Evidence) Group. Meta-analysis of relation of skipping breakfast with heart disease. Am J Cardiol 2019; 124(6):978-986.

4. Bi H, Gan Y, Yang C, Chen Y, Tong X, Lu Z. Breakfast skipping and the risk of type 2 diabetes: a meta-analysis of observational studies. Public Health Nutr 2015;18(16):3013-3019.

5. Rong S, Snetselaar LG, Xu G, et al. Association of skipping breakfast with cardiovascular and all-cause mortality. J Am Coll Cardiol 2019;73(16):20252032.

6. Ofori-Asenso R, Owen AJ, Liew D. Skipping breakfast and the risk of cardiovascular disease and death: a systematic review of prospective cohort studies in primary prevention settings. J Cardiovasc Dev Dis 2019;6(3):30.

7. Chen H, Zhang B, Ge Y, et al. Association between skipping breakfast and risk of cardiovascular disease and all-cause mortality: A meta-analysis. Clin Nutr 2020;39(10):2982-2988.

8. Johnsen NF, Frederiksen K, Christensen J, et al. Whole-grain products and whole-grain types are associated with lower all-cause and cause-specific mortality in the Scandinavian HELGA cohort. Br J Nutr 2015; 114(4):608-23.

9. Veronese N, Solmi M, Caruso MG, et al. Dietary fiber and health outcomes: an umbrella review of systematic reviews and meta-analyses. Am J Clin Nutr 2018;107(3):436-444.

10. Centers for Disease Control and Prevention. National Health and Nutrition Examination Survey (NHANES) Survey Methods and Analytic Guidelines. Available from: https://wwwn.cdc.gov/nchs/nhanes/ analyticguidelines.aspx. Accessed January 11, 2021.
11. Centers for Disease Control and Prevention. National Center for Health Statistics Data Linkage: Public-use Linked Mortality File. Available from: https://www.cdc.gov/nchs/data/datalinkage/publicuse-2015-linked-mortality-file-description.pdf. Updated March 2020. Accessed 01/11/2021.

12. Centers for Disease Control and Prevention. National Health and Nutrition Examination Survey (NHANES): 2001-2002 Data Documentation, Codebook and Frequencies. Available from: https:// wwwn.cdc.gov/Nchs/Nhanes/2001-2002/DRXTOT_ B.htm\#WTDR4YR. Accessed April 5, 2021.

13. American Heart Association. Whole Grains, Refined Gains, and Dietary Fiber. Available from: https:// www.heart.org/en/healthy-living/healthy-eating/eatsmart/nutrition-basics/whole-grains-refined-grainsand-dietary-fiber. Accessed April 7, 2021.

14. Quagliani D, Felt-Gunderson P. Closing America's fiber intake gap: communication strategies from a food and fiber summit. Am J Lifestyle Med 2016;11(1): 80-85.

15. Whelton PK, Carey RM, Aronow WS, et al. 2017 ACC/AHA/AAPA/ABC/ACPM/AGS/APhA/ASH/ ASPC/NMA/PCNA Guideline for the prevention, detection, evaluation, and management of high blood pressure in adults: a report of the American College Of Cardiology/American Heart Association Task Force on clinical practice guidelines [published correction appears in Hypertension. 2018 Jun; 71(6):e140-e144]. Hypertension 2018;71(6):e13e115.

16. American Diabetes Association. Classification and Diagnosis of Diabetes: Standards of Medical Care in Diabetes-2019. Diabetes Care 2019;42(Suppl 1):S13S28.

17. Cox D. Regression models and life tables. J R Statist Soc B 1972;34: 187-220.

18. Ma Y, Hébert JR, Li W, et al. Association between dietary fiber and markers of systemic inflammation in the Women's Health Initiative Observational Study. Nutrition 2008;24(10):941-949.

19. Ofori-Asenso R, Owen AJ, Liew D. Skipping breakfast and the risk of cardiovascular disease and death: A systematic review of prospective cohort studies in primary prevention settings. J Cardiovasc Dev Dis 2019;6(3):30.

20. King DE, Egan BM, Woolson RF, Mainous AG, Al-Solaiman Y, Jesri A. Effect of a high-fiber diet vs a fiber-supplemented diet on C-reactive protein level. Arch Intern Med 2007;167(5):502-506.

21. Chuang SC, Vermeulen R, Sharabiani MT, et al. The intake of grain fibers modulates cytokine levels in blood. Biomarkers 2011;16(6):504-510.

22. Margină D, Ungurianu A, Purdel C, et al. Chronic inflammation in the context of everyday life: dietary changes as mitigating factors. Int J Environ Res Public Health 2020;17(11):4135. 
23. Zhu S, Cui L, Zhang X, et al. Habitually skipping breakfast was associated with chronic inflammation: a cross-sectional study. Public Health Nutr 2020;1-8.

24. Lazarou C, Matalas AL. Breakfast intake is associated with nutritional status, Mediterranean diet adherence, serum iron and fasting glucose: the CYFamilies study. Public Health Nutr 2015;18(7):1308-1316.
25. Matheson EM, King DE, Everett CJ. Healthy lifestyle habits and mortality in overweight and obese individuals. J Am Board Fam Med 2012;25(1):9-15.

26. King DE, Mainous AG, 3rd, Matheson EM, Everett CJ. Impact of healthy lifestyle on mortality in people with normal blood pressure, LDL cholesterol, and Creactive protein. EurJ Prev Cardiol 2013;20(1):73-79. 